\title{
Acaricidal Effect of Commiphora swynnertonii Stem bark Exudate Against Rhipicephalus appendiculatus
}

\section{Sylvester G. Temba', Paul Erasto², Disela E. Swai', Musa Chacha* \\ 'School of Life Science and Engineering, Nelson Mandela African Institution of science and Technology P.O Box 477 Arusha, Tanzania. \\ ${ }^{2}$ National Institute for Medical Research (NIMR) P.O Box 9653 Dar es salaam, Tanzania. \\ Study Area: Monduli District, Arusha region, Tanzania \\ Coordinates: $4^{\circ} 24^{\prime} 36^{\prime} \mathrm{S} 37^{\circ} 10^{\prime} 48^{\prime} \mathrm{E}$}

Key words: Insect mortality, ticks, medicinal herb

\section{Introduction:}

In Africa, many societies depend on livestock keeping as a source of food, income and providing power for farming and other domestic benefits (Gonzo et al., 2014). Tick infestation and consequently, tick borne diseases have been a key bottleneck in livestock farming in Africa. Ticks are responsible in the transmission of East Coast Fever (ECF), babesiosis, anaplasmosis, dermatophilosis, and cowdriosis in the Sub Saharan Africa (Kalala et al., 2014; Mkangara et al., 2014). R. appendiculatus is hard tick mainly found in the ears of the cattle, buffalo, and antelope. It transmits a number of pathogens including Theileria parva (East coast fever), Nairobi sheep diseases virus and brown tick toxicosis (Yessinou, 2016). Tick and Tick borne diseases (TTBD) cause death of livestock, elevate the cost of veterinary services, reduce quality and quantity of the animal product, loss of labor animals and lower reproduction capability (Ilham et al., 2014; Kivaria, 2006; Mkangara et al., 2014). Reducing the incidence of TTBD leads to economic benef its such as increase quality of animal products, fertility, lowers cost of veterinary

\section{Abstract}

The objective of this study is to evaluate the acaricidal activity of Commiphora swynnertonii (Burseracea) stem bark exudates against Rhipicephalus appendiculatus. $C$. swynnertonii is a small woody plant found in arid and semiarid environments. It's fruits which are consumed by birds and animals. $R$. appendiculatus is the brown ear tick responsible for the transmission of east coast fever in cattle.This specie of tick is commonly found in the savannah and temperate climatic condition. C. swynnertonii exudate was prepared using soap solution and evaluated against the R.appendiculatus using adult immersion test method (AIT). The percent adult mortality within 15 days and percentage hatching of laid ova were determined at concentrations of $12.5,25,50,60,70,80,90$, and $100 \mathrm{mg} / \mathrm{ml}$. The results showed that mortality was significantly high at the concentration greater than $25 \mathrm{mg} / \mathrm{ml} \quad(\mathrm{p}<0.05)$, while inhibition of laid eggs was found to be significant at 90 and $100 \mathrm{mg} / \mathrm{ml}(\mathrm{p}<0.05)$. The C. swynnertonii exudates found to inhibit completely the hatching of tick's eggs. Conclusively, C.swynnertonii exudates have high acaricidal power against R.appendiculatus and can be employed as natural acaricides especially by smallholder farmers to control ticks.

services and increase manure production (Kivaria, 2006).

For many years, tick infestations has been controlled through the use of synthetic acaricides (Brito et al., 2011) usually suspended in water. Tick resistance to some common synthetic acaricides, the presence of acaricides residues on animal products and environmental contamination has been reported in the world (CastroJaner et al., 2010; Krishna et al., 2014; Lovis et al., 2011; Pretty \& Waibel, 2005). Resistance to synthetic acaricides has been linked to the multiple use and improper frequency application of synthetic acaricides to livestock (Eshetu et al., 2013). Development of acaricidal agents targeting eggs, larvae, nymph and adults is currently viewed as a sustainable means of controlling ticks (Habeeb, 2010; White et al., 2004). It is in this view that $C$. swynnertonii which is exploited by many African communities for ethnoveterinary use (Miller et al., 2002; Musa, 2008) was evaluated for acaricidal activity. Commiphora swynnertonii (family Burseracea) is a small woody plant which can grow up the height of 2.5 meter (Mukhlesur, et al., 2008; Van Wyk \& Wink, 2004). The

*Corresponding Author: musa.chacha@nm-aist.ac.tz 


\section{RESEARCH ARTICLE}

plants is found in the arid and semi-arid environment and grows with tiny leaves and spiny with fruits edible to birds and animals (Paraskeva, et al., 2008). C. swynnertonii claimed to be used as veterinary medicine (Deepa, et al., 2015). This paper therefore reports acaricidal activities of C.swynnertonii exudates against the $R$. appendiculatus.

\section{Materials and methods:}

Plant materials: the plant exudates were collected from the stem bark of $C$. swynnertonii at Mererani in Simanjiro District, Arusha region Tanzania. The C. swynnertonii plants were identif ied by botanist from Tropical Pesticide Research Institute (TPRI) Arusha Tanzania. The voucher specimen CS oo1 was deposited in the herbarium at Nelson Mandela African Institution of Science and Technology (NM-AIST) Arusha, Tanzania.

Preparation of acaricides: the extraction was done by using $10 \mathrm{mg} / \mathrm{ml}$ of a commercial powder soap OMO (purchased from Uniliver Kenya Ltd) prepared using distilled water. The following dilutions of exudate soap solutions were prepared 100, 90, 80, 70, 60, 50, 25 and 12.5 $\mathrm{mg} / \mathrm{ml}$. The dilutions prepared were used to test the ticks' percentage mortality, index of laying eggs, and inhibition of hatching by adult immersion test method (AIT).

Collection of ticks: the ticks were collected from smallholder farmers at Monduli District Arusha region. Ticks collected were stored in a small bottle closed with a muslin cloth to prevent from escape and transported to TPRI for identification. After Identification, the female R. appendiculatus were fed on the rabbit to engorge (Drummond et al., 1973; Reghu Ravindran et al., 2011). Ticks were incubated at biological oxygen demand (BOD) incubator at $28 \pm 2^{\circ} \mathrm{C}$ and relative humidity $(\mathrm{RH}) 80 \%$ to lay eggs. The eggs were incubated and hatch, the larva were fed to nymph and then to adult. The adults were fed on rabbit again to engorged and drop out. The engorged female ticks were transported to Nelson Mandela African Institution of Science and Technology laboratory, washed by distilled water and dried in by absorbent paper ready for the experiment (Abbas et al., 2014). A total of 216 adult engorged female ticks were used for this experiment.

Adult Immersion Test (AIT): the AIT was conducted according to FAO (1984) guidelines with minor modif ications (Miller et al., 2002; Ravindran et al., 2014). Four replicates of six ticks were used to test each extract concentration. The ticks were selected randomly and weight of each replicate of the female engorged ticks was recorded. Each replicate were immersed to the respective concentration (10 $\mathrm{ml}$ ) at room temperature for $10 \mathrm{~min}$ in a $50 \mathrm{ml}$ beaker with a gentle agitation according to (Hanus et al., 2005; Ravindran et al., 2014) with minor modifications. Ticks were recovered from the solutions and placed in plastic Petri-dishes. The control group was immersed in soap solution $(10 \mathrm{mg} / \mathrm{ml})$. Ticks were placed in a petri dish
Ambient Science, 2018: Vol. 05(1); 28-32 DOI:10.21276/ambi.2018.05.1.ra01

over Whatman's filter paper no 1 (purchased from Whatman international Ltd Maidstone England). The treated petri and untreated ticks were kept at room temperature for 24 hours, then the ticks were incubated in biological oxygen demand (BOD) incubators at $28 \pm 2^{\circ} \mathrm{C}$ and relative humidity $85 \pm 2 \%$. The ticks were observed for mortality and oviposition for the period of 15 days. After 15 days the percentage mortality was determined (Hanus et al., 2005). The weights of the eggs laid were recorded and were incubated for additional 30 days to estimate percentage hatching.

The index of laying eggs $(\mathrm{IE})=\frac{\text { Weight of the laid eggs }(\mathrm{g})}{\text { Weight of the females }(\mathrm{g})}$

Percentage inhibition of egg laying $=$

$$
\frac{(\text { IE control group }- \text { IE treated group })}{\text { IE control group }} \times 100
$$

After the period of thirty days the number of dead and live larvae and unhatched eggs were determined and percentages hatched eggs were calculated.

Estimated reproductive factor (ERF) and inhibition of reproduction (IR) were calculated using the formula belowas described by Drummond et al. (1973).

$\mathrm{ERF}=\underline{\mathbf{2 0}, 000 \mathrm{XY}}$

$$
\mathrm{Z}
$$

Where: 20,00o average number of eggs per gram

$\mathrm{X}=$ weight $(\mathrm{g})$ of the eggs produced

$\mathrm{Y}=$ estimated percentage hatchability of the eggs

$\mathrm{Z}=$ weight $(\mathrm{g})$ of the females

\section{Percentage inhibition reproduction $(\mathrm{IR})=$ (ERF control group - ERF treated group $) \times 100$ ERF control group}

Statistical analysis: Microsoft Excel 2013 computer software was used to obtain regression equation where LC 50 and LC 99 were calculated. One way analysis of variance (ANOVA) was carried out by Genstat software version 10 to determine significant differences among the doses in mortality, index of laying eggs, the percentage inhibition of laid eggs, hatching percentages and inhibition of hatching. The $\mathrm{p}$ values less than 0.05 was considered significant.

\section{Results :}

Mortality of ticks: Commiphora swynnertonii stem bark exudate was evaluated for acaricidal activity against $R$. appendiculatus. The findings emanated from this study are summarized in Table-1. The tested concentrations were prepared by dissolving a known amount of $C$. swynnertonii stem bark exudate in a known volume of diluted soap solution. It was evident that a complete mortality of ticks was observed at $100 \mathrm{mg} / \mathrm{ml}$ for the period of fifteen days of the experiment. Mortalities at higher concentrations (6o to $100 \mathrm{mg} / \mathrm{ml}$ ) waere significantly 
Table 1. Effect of commiphora Swynnertonii exudates against R. appendiculatus

\begin{tabular}{|c|c|c|c|c|c|c|}
\hline $\begin{array}{l}\text { Dose concentration } \\
(\mathrm{mg} / \mathrm{ml})\end{array}$ & $\begin{array}{l}\text { Percentage } \\
\text { Mortality }\end{array}$ & $\begin{array}{l}\text { Weight of the } \\
\text { laid eggs }(\mathrm{g})\end{array}$ & $\begin{array}{l}\text { Number of eggs } \\
\text { incubated }\end{array}$ & $\begin{array}{l}\text { Weights of the } \\
\text { females ticks (g) }\end{array}$ & $\begin{array}{l}\text { Index of } \\
\text { aid eggs }\end{array}$ & $\begin{array}{l}\text { Percentage } \\
\text { inhibition of egg laid }\end{array}$ \\
\hline 12.5 & $25 \mathrm{~cd}$ & $0.31 b$ & $13592 a$ & $1.45^{a}$ & $0.212 \mathrm{~d}$ & $-48 a$ \\
\hline 25 & $33.3 \mathrm{C}$ & $0.1 a$ & $4413 b c$ & $0.67 b$ & o.187cd & $-32 a b$ \\
\hline 50 & $41.7 \mathrm{C}$ & $0.05 \mathrm{~cd}$ & $2300 c$ & $0.56 b$ & o.o9gabcd & $27.2 \mathrm{bcde}$ \\
\hline 60 & $75^{b}$ & $0.16 b c$ & $6808 b$ & $1.23 a b$ & 0.128 bcde & 15.8abcd \\
\hline 70 & $87 \cdot 5 a b$ & o.o6cd & $2833 \mathrm{bc}$ & $1.07 a b$ & o.059abc & $62.6 \mathrm{cde}$ \\
\hline 80 & $87 \cdot 5 a b$ & $0.08 \mathrm{~cd}$ & $3573 \mathrm{bc}$ & $1.25 \mathrm{ab}$ & $0.064 a b c$ & 48.6cde \\
\hline 90 & $95.8 \mathrm{ab}$ & $0.03 d$ & $125 \mathrm{OC}$ & $1.63 a$ & $0.025 a b$ & 86de \\
\hline 100 & $100 a$ & $0.02 \mathrm{~d}$ & $576 c$ & $1.12 \mathrm{ab}$ & $0.08 a$ & 91e \\
\hline Control & o.od & $0.19 b$ & $7128 a$ & $1.2 \mathrm{ab}$ & o.157cde & o.oabc \\
\hline Mean & 61.11 & 0.11 & 4719 & 1.13 & 0.104 & 27.8 \\
\hline $\mathrm{CV} \%$ & 24.40 & 58.00 & 58.6 & $39 \cdot 3$ & 64.1 & $159 \cdot 3$ \\
\hline LSD (0.05) & 0.001 & 0.001 & 0.001 & 0.05 & 0.002 & 0.001 \\
\hline Fpr. & $* * *$ & $* * *$ & $* * *$ & * & $* *$ & $* * *$ \\
\hline
\end{tabular}

Values are expressed as mean \pm SEM, values with the same superscript within the column means do not show statistically significant differences $(\mathrm{p}>0.05)$

Table 2: Mean estimated reproductive factor and Inhibition of reproduction of R. appendiculatus engorged females subjected to different concentrations of $\mathrm{C}$. swynnertonii stem bark exudates.

\begin{tabular}{lcclllllllll}
\hline Dose $\mathrm{mg} / \mathrm{ml}$ & $\mathrm{o}$ & 12.5 & 25 & 50 & 60 & 70 & 80 & 90 & 100 & Mean \\
\hline $\mathrm{ERF} \pm \mathrm{SEM}$ & $314162.6 \pm 51456.6$ & $0 \pm 0$ & $0 \pm 0$ & $0 \pm 0$ & $0 \pm 0$ & $0 \pm 0$ & $0 \pm 0$ & $0 \pm 0$ & $0 \pm 0$ & $34907 \pm 17427.86$ & $*$ \\
$\mathrm{IR} \pm \mathrm{SEM}$ & $100 \pm 0$ & $100 \pm 0$ & $10 \pm 0$ & $100 \pm 0$ & $100 \pm 0$ & $100 \pm 0$ & $100 \pm 0$ & $100 \pm 0$ & $100 \pm 0$ & $*$ & \\
\hline
\end{tabular}

Values are expressed as mean $\pm \mathrm{SEM},{ }^{*}<0.05, \mathrm{ERF}=$ Effective reproductive factor, $\mathrm{IR}=$ Inhibition of reproduction

higher $(\mathrm{p}<0.001)$ than in lower concentrations. The mortality of ticks using synthetic acaricides (AlphaCypermethrin) was reported to be 100 percent within two days of exposure (Musa, 2008). The highest tick mortality of the tested C. swynnertonii stem bark exudate occurred between day one and day nine post-treatment. The lethal concentrations which can result in mortality for at least 50 and 99 percent ( $\left.\mathrm{LC}_{50}, \mathrm{LC}_{99}\right)$ of the ticks were established to be 42.9 and $92.8 \mathrm{mg} / \mathrm{ml}$ respectively (Fig.-1).

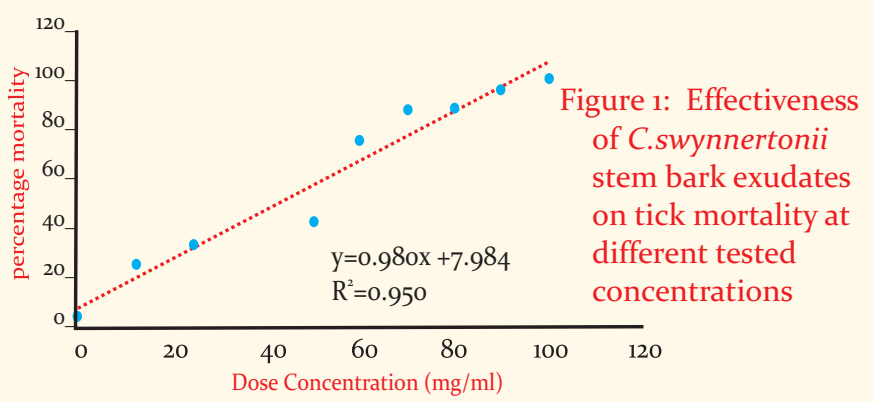

Effects of Commiphora swynnertonii exudates on tick's ability to lay eggs: C.swynnertonii exudate was evaluated for its effect on the ability of engorged female ticks to lay eggs. The body weights of engorged female ticks were not significantly different from each other. The engorged female ticks were treated with $25,50,60,70,80$, 90 , and $100 \mathrm{mg} / \mathrm{ml}$ of $C$. swynnertonii. The weights of the laid eggs were found to decrease as the tested concentration of C.swynnertonii stem bark exudates increased (Table-1). The weight of eggs laid by the treated engorged female ticks was found to be significantly different from those of untreated group $(\mathrm{p}<0.05)$.

The index of laid eggs by female ticks was affected by the concentration of $C$. swynnertonii exudates. The female ticks tested with high concentrations found to have lower ability to lay eggs as compared to those tested with lower concentrations of the exudates. The index of laying eggs of treated engorged female ticks with C.swynnertonii stem bark exudates at concentration 100 and $90 \mathrm{mg} / \mathrm{ml}$ was found to have the signif icant difference to those untreated group $(\mathrm{p}<0.05)$.

Hatching of the ticks eggs: eggs laid by both treated and un-treated engorged female ticks were incubated at $28 \pm 2$ oC for 30 days. On visual examination of the incubated eggs, it was observed that all eggs laid by ticks treated with C. swynnertonii stem bark exudates did not hatch while those eggs laid by untreated ticks were hatched (Table-2). C. swynnertonii stem bark exudate was found to interfere the development of eggs. The $C$. swynnertonii stem bark exudate lowers reproduction rates of the tick.

\section{Discussion:}

There is an increasing interest on the use of botanicals to control ectoparasite as they are found to be relatively cheaper, eco-friendly, effective, readily available and safe especially for smallholder farmers (Shyma et al., 2014). Plants contain a range of chemically active ingredients 


\section{RESEARCH ARTICLE}

which can intervene all biological process of the ticks interrupting its life cycle and its dispersal (Habeeb, 2010). In the current study, C.swynnertonii exudate was evaluated for acaricidal activity against $R$.appendiculatus. The findings showed that C.swynnertonii exudates induces tick mortality, lowers ticks ability to lay eggs and affects the viability of laid eggs from the treated engorged female ticks. Previous phytochemical studies on Commiphora spp. reported on the presence of several classes of secondary metabolites namely alkaloids, saponins, tannins, anthraquinones, cardiac glycosides, terpenes, steroids, resin acids and phenolics which found to cause mortality in arthropods (Hanus et al., 2005; Krishna et al., 2014; Musa, 2008; Shyma et al., 2014). Moreover, it was reported that Commiphora spp. possessing antibacterial and antifungal activities (Bakari et al., 2012). The acaricidal effect of C.swynnertonii exudate was due to the presence of tannins, saponin, terpenes, and flavonoids (Bakari, 2013; Bissinger \& Roe, 2010). The observed mortality of ticks may be accounted by several possible mechanisms working separately or working in synergic (Chandler et al., 2011; Kunz \& Kemp, 1994). In some cases, insecticides can have both insecticidal and acaricidal properties (George et al., 2014). It is believed that the mechanism of action of terpenoids and flavonoids might be similar to that of the organophosphate compounds. Therefore the acaricidal activities observed in this experiment might be contributed by one or more bioactive compounds present in C. swynnertonii exudate.

The mortality of the ticks when immersed in the C. swynnertonii stem bark exudates suggests that there is contact effect of the exudates. At higher concentration the effect of the exudates was immediate while at a lower concentration the effect was taking place slowly as the residual on the body stimulate effect. The variation in mortality based on concentration was attributed to the amount of the exudates in contact with the body and penetrates to the inner cells. The amount of bioactive compounds of the exudates penetrates the inner cell is proportional to mortality caused thus exudates with higher concentration results in mortalities earlier than those with lower concentrations. Higher concentration is recommended to be used as lower concentration may result in resistance especially when the activity is not taking place shortly. The mode of action was similar to that of pyrethroids in insect where by it produces hyperexcitation tremors and paralysis followed by mortality (Shyma et al., 2013). The nerve excitations occurs as a result of a change in membrane permeability to sodium and potassium ions (Krishna et al., 2014). The use of OMO (detergent) is recommended as it has lipophilic properties which can remove the outside waxy cuticle layer of the ticks and allow the bioactive compounds to
Ambient Science, 2018: Vol. 05(1); 28-32 DOI:10.21276/ambi.2018.05.1.ra01

penetrate to the inner cells. Bioactive compounds revealed to interfere with basic metabolic, biochemical, physiological and behavioral functions of the ticks. The penetration of the bioactive compounds through the outer layer of the ticks causes the mortalities, suppress and reduction in oviposition as well as the development of the eggs hence blocking of the eggs hatching. The bioactive present in the exudates suggests interfering the ovaries as well as the egg formations (Shyma et al., 2014).

This study supports the use C.swynnertonii as a potentially acaricidal agent for controlling $R$. appendiculatus and confirm the presence of some factors in the exudates with an acaricidal property. Exudates having acaricidal, anti-oviposition, and inhibition of fecundity properties may make the plant valuable component of developing valuable strategies for integrated tick management.

\section{Conclusion:}

The obtained results indicate that $C$. swynnertonii exudates may prove to be effective against control $\mathrm{R}$. appendiculatus. Therefore smallholder farmer especially those practice zero grazing, in the remote settings where synthetic acaricides are unaffordable or unavailable, they can use C. swynnertonii exudate to control ticks. Further studies should be conducted to determine the mechanism of C. swynnertonii exudates mode of actions. However, plants from different parts should be studied to conf irm if they have the sameactivity. Field trial should be conducted to compare the results with laboratory results.

\section{Acknowledgements:}

Authors acknowledge the Regional University Forum for Capacity building in agriculture (RUFORUM) through RUFORUM Commiphora Acaricidal Assay (ROFORUM CAA) project RU 2015 GRG-127 for funding this study. Nelson Mandela African Institution of Science and Technology (NM-AIST) for granting permission for studies. Thanks are also due for Innocent Mboya and Ibrahim Hamis a botanists and entomologists respectively from Tropical Pesticides Research Institute (TPRI), Arusha. Dr. Beatus Lyimo, Samson Lyimo, John Mshanga, Lydia Munuo, Philipo Mashamba, from NM-AIST as well as Shaban Muller and Dr. Modester Damas for their support.

\section{References:}

Abbas, R.Z., Zaman, M.A., Colwell, D.D., Gilleard, J. \& Iqbal, Z. (2014): Acaricide resistance in cattle ticks and approaches to its management: the state of play. Vet Parasitol.,203(1,2):6-20.

Bakari, G. (2013): Biological activity of extract from Commiphora swynnertonii against microbes of veterinary importance in chickens. $\mathrm{PhD}$ Thesis. Sokoine University of agriculture, Tanzania.

Bakari, G., Max, R.A., Mdegela, H.R., Phiri, E.C., \& Mtambo, M.M. (2012): Effect of crude extracts from Commiphora swynnertonii (Burtt) against selected microbes of animal health importance. L. Med. Plants Res., 6(9), 1795-1799.

Bissinger, B.W. \& Roe, R.M. (2010): Tick repellents: past, present, and future. Pestici. Biochem. Physiol., 96(2),:63-79. 
Brito, L.G., Barbieri, F.S., Rocha, R.B., Oliveira, M.C.S., \& Ribeiro, E.S. (2011): Evaluation of the Efficacy of Acaricides Used to Control the Cattle Tick, Rhipicephalus microplus, in Dairy Herds Raised in the Brazilian Southwestern Amazon. Vet. Med. Int., Article ID 806093.

Castro-Janer, E., Martins, J. R., Mendes, M. C., Namindome, A., Klafke, G. M., \& Schumaker, T.T.S. (2010): Diagnoses of fipronil resistance in Brazilian cattle ticks (Rhipicephalus (Boophilus) microplus) using in vitro larval bioassays. Vet. Parasitol., 173(3-4):300-306.

Chandler, D., Bailey, A. S., Tatchell, G.M., Davidson, G., Greaves,J., \& Grant, W.P. (2011): The development, regulation and use of biopesticides for integrated pest management. Philos. Trans. R.Soc. Lond. B. Biol. Sci., 366(1573):1987-1998.

Deepa J., Gokulakrishnan J., Baranitharan M., Dhanasekaran S. (2015): Larvicidal activity of Indian medicinal plants on the Dengue fever mosquito Aedes aegpti Linnaeus. Int. J. Pure App. Zool., 3(2) 130-136.

Drummond, R.O., Ernst, S.E., Trevino, J.L., Gladney, W.J., \& Graham, O.H. (1973): Boophilus annulatus and B. microplus: laboratory tests of insecticides. J. Econ. Entomol., 66(1):130133 .

Eshetu, E., Dinede, G., Lakew, M. \& Tolosa, T. (2013): In-vitro efficacy evaluation of amitraz $0.025 \%$ and diazinon $0.06 \%$ against Rhipicephaluspulchellus and Amblyommagemma in Borena pastoral area, Southern rangeland of Ethiopia. I Parasitol. Vector. Biol., 5: 72-76.

George, D.R., Finn, R.D., Graham, K.M. \& Sparagano, O.A. (2014): Present and future potential of plant-derived products to control arthropods of veterinary and medical significance. Parasite Vector., 7 (28).

Gonzo, L., Mukwembi, P., Mashiri, C., Hellen, M., Chandiwana, E., Chipato, S. \& Mpondo, C. (2014): Comparison of the performance of garlic, tobacco and tephrosia as natural tick control biocides on mashona cows. Int. J. Math. Arch., 5(2), 218-226.

Habeeb, S.M. (2010): Ethno-vetrterinary and Medicinal Knowledge of Crude Plant Extracts and its Methods of Application (Traditional and Morden) for Tick control. World Appl. Sci.J., 11(9), 1047-1054.

Hanus, L. O., Rezanka, T., Dembitsky, V. M., \& Moussaieff, A. (2005): Myrrh Commiphora chemistry. Biomed. Papers, 149(1), 3-28.

Ilham, M., Razzig, A., Elhaj, M., \& Mohammed, Y. (2014): Acaricidal Activity of Crude Extract of Annona Squamosa against Hyalomma Anatolicum (Ixodoidea: Ixodidae). Altern. Integr. Med. 3:173.

Kalala, W., Magadula, J. \& Mdegela, H. (2014). Evaluating Acaricidal Activity of Commiphora swynertonii (Burrt.) bark Exudate against common Ticks in Tanzania. Int. J. Herbal Med., 2(4):19-25.

Kivaria, F.M. (2006): Estimated direct economic costs associated with tick-borne diseases on cattle in Tanzania. Trop. Anim. Health Prod. 38(4):291-299.

Krishna, T. P. A., Krishna, T. P. A., Chithra, N. D., Deepa, P. E., Darsana, U., Sreelekha, K. P., Ghosh, S. (2014): Acaricidal activity of petroleum ether extract of leaves of Tetrastigma leucostaphylum (Dennst.) Alston against Rhipicephalus (Boophilus) annulatus. Scientific. World J., Article ID 715481.
Kunz, S.E. \& Kemp, D.H. (1994): Insecticides and acaricides: resistance and environmental impact. Rev. Sci. Tech. Off. Int. Epiz., 13(4):1249-1286

Lovis, L., Perret, J.L., Bouvier, J., Fellay, J.M., Kaminsky, R., Betschart, B. \& Sager, H. (2011): A new in vitro test to evaluate the resistance level against acaricides of the cattle tick, Rhipicephalus (Boophilus) microplus. Vet Parasitol., 182(24):269-280.

Miller, R.J., Davey, R.B. \& George, J.E. (2002): Modification of the Food and Agriculture Organization Larval Packet Test to Measure Amitraz-Susceptibility Against Ixodidae. L. Med. Entomol.39(4):645-651.

Mkangara, M., Erasto, P., \& Chacha, M. (2014): Acaricidal Activity of Commiphora Swynnertonii (Burtt) Stem Bark Extracts against adult Rhipicephalus appendiculatus Newman and Amblyomma variegatum. Am. J. Res. Comm., 2(9):82-92.

Musa, A.A. (2008): Antioxidant and Antibacrerial activity of Commiphora kerstingii Engl. Stem back Extract. Res. J. Phytochem., 2(2), 106-111.

Paraskeva, M.P., van Vuuren, S.F., van Zyl, R.L., Davids, H. \& Viljoen, A.M. (2008): The invitro biological activity of selected South African Commiphora species. I. Ethnopharmacol., 119(3):673-679.

Pretty, J. \& Waibel, H. (2005). Paying the Price: The Full Cost of Pesticides. The Pesticide Detox. Pub. by: Earthscan,UK \& USA

Ravindran, R., Juliet, S., Gopalan, A.K.K., Kavalimakkil, A.K., Ramankutty, S.A., Nair, S.N., Narayanan, P.M. \& Ghosh, S. (2011): Toxicity of DMSO, Triton X 100 and Tween 20 against Rhipicephalus (Boophilus) annulatus. J. Parasitic Dis., 35(2):237-239.

Ravindran, R., Ramankutty, S.A., Juliet, S., Palayullaparambil, A.K.T., Gopi, J., Gopalan, A.K.K., Nair, S.N. \& Ghosh, S. (2014): Comparison of in vitro acaricidal effects of commercial preparations of cypermethrin and fenvalerate against Rhipicephalus (Boophilus) annulatus. SpringerPlus, 3:90.

Shyma, K., Gupta, J., Ghosh, S., Patel, K., \& Singh, V. (2014). Acaricidal effect of herbal extracts against cattle tick Rhipicephalus ( Boophilus ) microplus using in vitro studies. Parasitol. Res., 113(5):1919-1926.

Shyma, K.P., Gupta, J.P. \& Singh, V. (2013). Breeding strategies for tick resistance in tropical cattle: a sustainable approach for tick control.J. Parasit. Dis. 39(1):1-6.

Van Wyk, B.-E. \& Wink, M. (2004): Medicinal plants of the wiorld. An illustrateted scientific guide to important medicinal plants and their uses. Pub. by: Timber Press, Portland, Oregon. Pp.48o

White,W.H., Plummer, P.R., Kemper, C.J., Miller, R.J., Davey, R.B., Kemp, D.H., Hughes, S., Smith, C.K. \& Gutierrez, J.A.(2004): An In Vitro Larval Immersion Microassay for Identifying and Characterizing Candidate Acaricides. L. Med. Entomol., 41(6):1034-1042 .

Yessinou, E.R., Akpo, Y., Adoligbe, C., Adinci, J., Assogba, M.N., Kountihouin, B., Karim I.Y.A. \& Farougou, S. (2016): Ressistance of ticks Rhipicephalus microplus to acaricides and control strategies. J. Entomol. Zool. Stud., 4(6):408-414. 